\title{
Analysis of Tensegrity Structures with Redundancies, by Implementing a Comprehensive Equilibrium Equations Method with Force Densities
}

\author{
Miltiades Elliotis, ${ }^{1}$ Petros Christou, ${ }^{2}$ and Antonis Michael ${ }^{2}$ \\ ${ }^{1}$ Department of Mathematics and Statistics, University of Cyprus, Nicosia, Cyprus \\ ${ }^{2}$ Department of Civil Engineering, Frederick University, Nicosia, Cyprus \\ Correspondence should be addressed to Miltiades Elliotis; melliotis@moi.gov.cy
}

Received 26 April 2016; Revised 26 July 2016; Accepted 19 October 2016

Academic Editor: Hassan Safouhi

Copyright (C) 2016 Miltiades Elliotis et al. This is an open access article distributed under the Creative Commons Attribution License, which permits unrestricted use, distribution, and reproduction in any medium, provided the original work is properly cited.

\begin{abstract}
A general approach is presented to analyze tensegrity structures by examining their equilibrium. It belongs to the class of equilibrium equations methods with force densities. The redundancies are treated by employing Castigliano's second theorem, which gives the additional required equations. The partial derivatives, which appear in the additional equations, are numerically replaced by statically acceptable internal forces which are applied on the structure. For both statically determinate and indeterminate tensegrity structures, the properties of the resulting linear system of equations give an indication about structural stability. This method requires a relatively small number of computations, it is direct (there is no iteration procedure and calculation of auxiliary parameters) and is characterized by its simplicity. It is tested on both $2 \mathrm{D}$ and $3 \mathrm{D}$ tensegrity structures. Results obtained with the method compare favorably with those obtained by the Dynamic Relaxation Method or the Adaptive Force Density Method.
\end{abstract}

\section{Introduction}

Cable networks [1-3] and tensegrity structures [4] are different from conventional structures, such as spatial steel frames or space steel trusses, in that they are lightweight structures with members which transmit only tension (cables and strings) or elements which transmit compression (bars before buckling). In this article, we are studying only the behavior of tensegrity structures. These structures are usually defined as planar or spatial trusses with a discontinuous set of members under compression, inside a continuous network of members under tension. The word tensegrity is an artificial word and it combines the words "tension" and "integrity." This word was coined several decades ago. Professor Fuller, in the United States, was essentially involved in the invention of this technical word. In one of his last books, Fuller described the compression members as "islands of compression in a sea of tension" [4]. Using the same concept, Emmerich [5] presented, in France in 1963, his own tensegrity patent. Snelson, one of Fuller's students, describes this type of structures as "continuous tension and discontinuous compression structures" [6].

Pretension, applied by means of tension members, plays an essential role in the structural behavior of the tensegrities. For the design of such structures, their stability is investigated under both static and dynamic loads. During the last decades, many methods have been proposed for the analysis of the tensegrities. One of the most important methods is the Dynamic Relaxation Method (DRM) which was used in this research for checking the numerical results obtained with the numerical scheme proposed in the present work. DRM is one of the classical techniques. It belongs to the family of methods under the title of three-term recursive formulae. It is an iterative procedure which is based on the fact that a system undergoing damped vibration, excited by a constant force, ultimately comes to rest in the displaced position of static equilibrium, obtained under the action of the constant force. One of the numerous first papers, written by pioneers of this method, is that of Papadrakakis [7] which proposes an automatic procedure for the evaluation 
of the iteration parameters and it is mentioned here (without underestimating the importance of other works in this domain) as an example of an article which presents in a strict, clear, and academic manner the way of implementing this numerical procedure. Recent research, performed in the domain of tensegrities, has given some new important techniques. However, a general review of the older and of the recent numerical schemes, developed in this area, is out of the scope of the present paper. Juan and Mirats Tur present an excellent review in their work [8] of the basic issues about the statics of tensegrity structures. Among the new methods, presented in literature during the last few years, is that of Zhang and Ohsaki [9] which is also considered in the present research for comparison purposes. Their method is an Adaptive Force Density Method (AFDM). It first finds a set of axial forces compatible with a given structure and then estimates the corresponding nodal coordinates under equilibrium conditions and constraints.

The technique implemented in the present work is a force density method which belongs to the class of the Equilibrium Equations Methods with Force Densities (EEMFD). With this method, the system of equilibrium equations is created by considering the equilibrium of forces in all the joints. The redundancies are treated by employing Castigliano's second theorem which gives the additional equations required to have a solution [10]. The partial derivatives, which appear in the additional equations, are numerically replaced by statically acceptable internal forces acting along the members. Also, the properties of the matrix of the system of linear equations are exploited because they give a strong indication of the stability of the structure.

The assumptions adopted in the present research are the following:

(1) Joints are frictionless but their mass is considered in calculations unless otherwise specified.

(2) The self-weight of a member (for structures within earth's gravity field) is not neglected unless otherwise specified. It is equally distributed at its ends.

(3) Live loads and pretensions on a member are transferred to the joints. They are equally distributed at the ends of the member.

(4) Displacements on the joints and deformations of the members of the structure are relatively small compared with the dimensions of the structure.

(5) The axial force carried by a member is constant along its length.

(6) The materials used, for all members of the structure, obey Hooke's Law for loadings below the yield stress.

The efficiency of this technique is based on its simplicity and the small number of calculations required. Thus, the objective is (i) to present the general idea and formulation and (ii) to test the method in planar and spatial tensegrity structures of any type of complexity and to compare it with the DRM or the AFDM.

The outline of the rest of this paper is as follows: in Section 2 we develop the formulation of a Comprehensive Equilibrium Equations Method with Force Densities

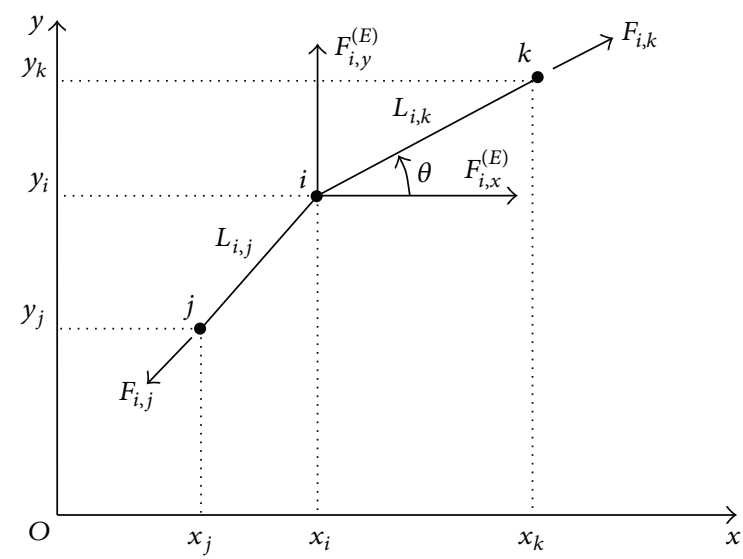

FIGURE 1: Equilibrium of an unconstrained node of a 2D tensegrity structure.

(CEEMFD) and in Section 3 we discuss the treatment of redundancies and we investigate the stability in this type of structures. In Section 4, some applications of the method are presented on planar and on spatial tensegrity structures. The article ends with Section 5 in which conclusions and proposals for future work are given.

\section{A Comprehensive Equilibrium Equations Method with Force Densities}

An important concept related with tensegrity structures is the "force density" [1-3]. For a member made of a material obeying Hooke's Law, with ends at $i$ and $j$ and with a length $L_{i, j}$ and a longitudinal force $F_{i, j}$, the force density is defined as follows:

$$
q_{i, j}=\frac{F_{i, j}}{L_{i, j}}=(E A)_{i, j} \frac{\varepsilon_{i, j}}{L_{i, j}}
$$

where $\varepsilon_{i, j}$ is the strain, $E$ is the Young modulus [10], and $A$ is the effective cross-sectional area of the member. This definition will be useful in the analysis which is presented herewith. Force density has a negative sign in compression and a positive sign in tension.

Figure 1 is used to exemplify the equilibrium of a typical unconstrained node $i$, on the $O x y$ plane, which is connected to joints $j$ and $k$, through members which have lengths $L_{i, j}$ and $L_{i, k}$. For the three-dimensional orthogonal Cartesian coordinate system $O x y z$, where $N_{m}$ joints are connected with joint $i$, through $N_{m}$ members, the equilibrium equations, in the direction of the axes $O x, O y$, and $O z$ are given by

$$
\begin{aligned}
\sum_{j=1}^{N_{m}} \frac{x_{i}-x_{j}}{L_{i, j}} F_{i, j} & =\sum_{j=1}^{N_{m}}\left(x_{i}-x_{j}\right) q_{i, j} \\
& =\sum_{j=1}^{N_{m}} q_{j, i} x_{i}-\sum_{j=1}^{N_{m}} q_{i, j} x_{j}=F_{i, x}^{(E)},
\end{aligned}
$$




$$
\begin{aligned}
\sum_{j=1}^{N_{m}} \frac{y_{i}-y_{j}}{L_{i, j}} F_{i, j} & =\sum_{j=1}^{N_{m}}\left(y_{i}-y_{j}\right) q_{i, j} \\
& =\sum_{j=1}^{N_{m}} q_{j, i} y_{i}-\sum_{j=1}^{N_{m}} q_{i, j} y_{j}=F_{i, y}^{(E)}, \\
\sum_{j=1}^{N_{m}} \frac{z_{i}-z_{j}}{L_{i, j}} F_{i, j} & =\sum_{j=1}^{N_{m}}\left(z_{i}-z_{j}\right) q_{i, j}=\sum_{j=1}^{N_{m}} q_{j, i} z_{i}-\sum_{j=1}^{N_{m}} q_{i, j} z_{j} \\
& =F_{i, z}^{(E)},
\end{aligned}
$$

where $i=1, \ldots, N$ and $N$ is the total number of nodes on the structure. In equations (2), (3), and (4) forces $F_{i, x}^{(E)}, F_{i, y}^{(E)}$, and $F_{i, z}^{(E)}$ are the external loads which include gravity loads, live loads, pretension, and even reactions in the case where the node is a support. Gravity loads are assumed to act along the negative $y$-axis, for $2 \mathrm{D}$ structures or along the negative $z$-axis for 3D structures. External loads, which appear on the right hand side of (2), (3), and (4) have the following general expressions:

$$
\begin{aligned}
F_{i, x}^{(E)}= & -\sum_{j=1}^{N_{m}}\left(x_{i}-x_{j}\right) t_{i, j}+B_{i, x}+R_{i, x}, \\
F_{i, y}^{(E)}= & -\sum_{j=1}^{N_{m}}\left(y_{i}-y_{j}\right) t_{i, j}+B_{i, y}+R_{i, y}, \\
F_{i, z}^{(E)}= & -G_{i}-\frac{1}{2} \sum_{j=1}^{N_{m}} w_{i, j} L_{i, j}-\sum_{j=1}^{N_{m}}\left(z_{i}-z_{j}\right) t_{i, j}+B_{i, z} \\
& +R_{i, z},
\end{aligned}
$$

where $G_{i}$ is the self-weight of joint $i$ and $w_{i, j}$ is the weight per unit length of a member with nodes at $i$ and $j$. Also, $t_{i, j}$ is the pretension per unit length of a member joining nodes $i$ and $j$. Forces $B_{i, x}, B_{i, y}$, and $B_{i, z}$ are the concentrated live loads and $R_{i, x}, R_{i, y}$, and $R_{i, z}$ are the reaction forces (if they exist) on joint $i$. Both live loads and reaction forces are assumed to be acting along the positive directions of axes $\mathrm{O} x, \mathrm{O} y$, and $\mathrm{O} z$.

The equilibrium of the whole structure is considered by introducing the connectivity matrix $P$. This matrix has elements $p_{a, c}$. Index $a$ takes values from 1 to $N_{b}$ (here $N_{b}$ is the number of all members) and index $c$ takes values from 1 to $N$. The elements $p_{a, c}$ of matrix $P$ take the following values [1-3]:

$$
p_{a, c}= \begin{cases}+1 & \text { if } c \text { is the initial node of member } a \\ -1 & \text { if } c \text { is the final node of member } a \\ 0 & \text { if } c \text { does not belong to member } a\end{cases}
$$

It really does not matter which node of member $a$ we consider first or last but once we consider a node $c$ to be the initial node for the member, we also consider it as the initial node for any other member that is connected with this node.

Also, matrix $S$ is introduced which has elements $s_{e, d}$. Index $e$ takes values from 1 to $N$ and index $d$ takes values from 1 to $N_{s}$ (where $N_{s}$ is the number of supports of the structure). Elements $s_{e, d}$ of matrix $S$ are then defined as follows:

$$
\begin{aligned}
& s_{e, d} \\
& = \begin{cases}-1 & \text { if node } e \text { coincides with the support } d \\
0 & \text { if node } e \text { is a different node from support } d .\end{cases}
\end{aligned}
$$

By introducing vectors $x_{c}, y_{c}$, and $z_{c}$ which contain the $x$ coordinates, $y$-coordinates, and $z$-coordinates, respectively, of all the $N$ nodes of the structure, the set of linear equilibrium equations for all the joints of the structure can be expressed in block form as shown below:

$$
A \cdot Q_{f}=\left[\begin{array}{cccc}
P^{T}\left(P \cdot x_{c}\right)_{s q} & S & O & O \\
P^{T}\left(P \cdot y_{c}\right)_{s q} & O & S & O \\
P^{T}\left(P \cdot z_{c}\right)_{s q} & O & O & S
\end{array}\right] \cdot\left[\begin{array}{c}
q \\
R_{x} \\
R_{y} \\
R_{z}
\end{array}\right]=\Psi^{(E)},
$$

where vector $Q_{f}$ contains all the force densities and reaction forces of the structure. For spatial tensegrities it has dimensions $\left(N_{b}+3 N_{s}\right) \times 1$. Vector $q$ contains all the unknown force densities $q_{i, j}$ which are inserted in $q$ according to the ascending order of numbering of the elements of the structure and it has dimensions $N_{b} \times 1$. Vectors $R_{x}, R_{y}$, and $R_{z}$ contain the reaction forces on the supports and each one of them has dimensions $N_{s} \times 1$. Vector $\Psi^{(E)}$ contains all the known external loads acting in the $x, y$, and $z$-directions, respectively, on all the joints of the structure (gravity loads, live loads, pretension, etc.) and for $3 \mathrm{D}$ tensegrities it has dimensions $3 N \times 1$. Its components $\Psi_{i, x}^{(E)}, \Psi_{i, y}^{(E)}$, and $\Psi_{i, z}^{(E)}$ have the same expression as for $F_{i, x}^{(E)}, F_{i, y}^{(E)}$, and $F_{i, z}^{(E)}$ in equations (2), (3), and (4), respectively, except that they do not contain the reaction forces. Matrix $A$ is the global shape matrix of the tensegrity and is very sparse. This means a significantly smaller number of computations and memory space on a computer compared with the classical finite element method. For the creation of a computer code, definitions (6) and (7) and formulation (8) are easy to use.

In the case of statically determinate structures, the set of linear equilibrium equations (8) is the set of equations to solve to directly find the unknown values of the force densities $q_{i, j}$. Considering all the $N$ joints of the structure and with the help of matrix $P$, the set of equilibrium equations (2), (3), and (4), for the whole structure, takes the following block form:

$$
\left[\begin{array}{lll}
D & O & O \\
O & D & O \\
O & O & D
\end{array}\right] \cdot\left[\begin{array}{l}
x_{c} \\
y_{c} \\
z_{c}
\end{array}\right]=\left[\begin{array}{l}
F_{x}^{(E)} \\
F_{y}^{(E)} \\
F_{z}^{(E)}
\end{array}\right]=\left[\begin{array}{l}
\left(R_{x}\right)_{\mathrm{gl}}+\Psi_{x}^{(E)} \\
\left(R_{y}\right)_{\mathrm{gl}}+\Psi_{y}^{(E)} \\
\left(R_{z}\right)_{\mathrm{gl}}+\Psi_{z}^{(E)}
\end{array}\right],
$$

where $\left(R_{x}\right)_{\mathrm{gl}},\left(R_{y}\right)_{\mathrm{gl}}$, and $\left(R_{z}\right)_{\mathrm{gl}}$ are global vectors of dimensions $N \times 1$ which contain the unknown reaction forces. Also, matrix $D$, which is known as the force density matrix (FDM) of the tensegrity, relates the nodal coordinates and the forces which are acting on the structure and is given by

$$
D=P^{T} \operatorname{diag}(q) P \text {. }
$$


The elements $d_{i, j}$ of matrix $D$ are as follows [1-3]:

$$
\begin{aligned}
& d_{i, j} \\
& = \begin{cases}-q_{i, j} & \text { when } i \neq j \\
\sum_{\substack{p=1 \\
(p \neq i)}}^{N_{m}} q_{p, j} & \text { when } i=j \\
0 & \text { if nodes } i \text { and } j \text { are not connected. }\end{cases}
\end{aligned}
$$

Matrix $D$ is a Kirchhoff matrix and it is a symmetric positive semidefinite matrix. It is also called discrete matrix or combinatorial Laplacian or admittance matrix and it contains elements with a positive or a negative sign [8]. It has dimensions $N \times N$. A more general form of (9) is the following:

$$
(I \otimes D) \cdot\left[\begin{array}{c}
x_{c}-D^{-1}\left(R_{x}\right)_{\mathrm{gl}} \\
y_{c}-D^{-1}\left(R_{y}\right)_{\mathrm{gl}} \\
z_{c}-D^{-1}\left(R_{z}\right)_{\mathrm{gl}}
\end{array}\right]=\left[\begin{array}{c}
\Psi_{x}^{(E)} \\
\Psi_{y}^{(E)} \\
\Psi_{z}^{(E)}
\end{array}\right]=\Psi^{(E)},
$$

where $I$ is the $3 \times 3$ unit matrix. So, equations (8) and (12) give the following elegant and important, at the same time, relation:

$$
(I \otimes D) \cdot\left[\begin{array}{c}
x_{c}-D^{-1}\left(R_{x}\right)_{\mathrm{gl}} \\
y_{c}-D^{-1}\left(R_{y}\right)_{\mathrm{gl}} \\
z_{c}-D^{-1}\left(R_{z}\right)_{\mathrm{gl}}
\end{array}\right]-A \cdot Q_{f}=0 .
$$

One may observe that equation (13) does not contain any values of the external loads except from the reaction forces on the supports.

\section{Redundancies, Numerical Representation of Castigliano's Second Theorem, and Stability}

The values of the elements of matrix $A$ in (8) depend directly on the values of the coordinates of the nodes. For planar problems it has dimensions $2 N \times\left(N_{b}+2 N_{s}\right)$ and for spatial structures it is of dimensions $3 N \times\left(N_{b}+3 N_{s}\right)$. For the statically determinate structures [10] and after inserting in the set of equations (8) the known values of reactions on the supports, matrix $A$ is reduced to a square matrix $\mathbf{K}_{e}$ of dimensions $2 N \times 2 N$, in two dimensions and $3 N \times 3 N$ in three dimensions. Its properties, as a square matrix, give important information about the stability of the form of the structure under study. So, for statically determinate structures, the set of linear equilibrium equations (8) has a solution if and only if $\operatorname{det}\left|\mathbf{K}_{e}\right| \neq 0$. Other equivalent conditions concerning square matrix $\mathbf{K}_{e}$, which secure the existence of a solution are given in many references about numerical analysis (e.g., [11]). If matrix $\mathbf{K}_{e}$ has a determinant equal to zero then, most probably, the structure is unstable.

For the 2D case, the degree of redundancy is $N_{r}=N_{b}+$ $N_{\mathrm{ur}}-2 N$ and for the $3 \mathrm{D}$ problems it is $N_{r}=N_{b}+N_{\mathrm{ur}}-$ $3 N$, where $N_{\mathrm{ur}}$ is the number of unknown reaction forces on the supports. We say that the system of linear equations has $N_{r}$ parametric solutions. Thus, we need an additional number of $N_{r}$ equations which, in this study, are provided by Castigliano's second theorem. According to this theorem, which is well presented in many classical books about solid mechanics (e.g., Zhang and Ohsaki [9]), all the forces in the bars or strings of the structure are expressed in terms of any $N_{r}$, in number, forces $Q^{(k)}$, which are considered as redundancies and are arbitrarily chosen among the $N_{b}$ forces $Q_{i}$, acting as internal loads along the members of the structure. It is assumed that no local mechanisms are formed. Then, Castigliano's second theorem gives the additional $N_{r}$ equations which are

$$
\frac{\partial U}{\partial Q^{(k)}}=\sum_{i=1}^{N_{b}} \frac{Q_{i}}{(E A)_{i}} \cdot \frac{\partial Q_{i}}{\partial Q^{(k)}} L_{i}=0, \quad k=1, \ldots, N_{r}
$$

where $U$ is the total potential energy of the structure. Internal forces $Q_{i}$ are then expressed as

$$
Q_{i}=Q_{i}^{(\mathrm{RL})}+\sum_{j=1}^{N_{r}} Q_{i}^{(j)} Q^{(j)}, \quad i=1, \ldots, N
$$

where $Q^{(j)}$ are the unknown internal redundant forces. In (15) forces $Q_{i}^{(\mathrm{RL})}$ represent a set of forces acting along each member $i$ and being in equilibrium with all other real forces acting on the same node. This set of forces is created by removing the redundancies and solving the resulting statically determinate structure (which is now called fundamental structure) under the action of its real loading. Then, solution gives the values of $Q_{i}^{(R L)}$. Also, in (15) forces $Q_{i}^{(j)}$ represent a set of forces in static equilibrium which appears when no real loading is applied on the fundamental structure and when the redundancy members (one at a time) are replaced with a pair of unit forces, opposing each other and acting along the member's axis. One such pair of forces is acting each time and for each pair the fundamental structure is solved. Forces $Q_{i}^{(j)}$ are then considered as quantities without the unit of force. They are used as the coefficients of $Q^{(j)}$ and their values constitute a group of statically acceptable internal forces, acting along the redundant members. Then, the partial derivative of $Q_{i}$ with respect to $Q^{(k)}$ in (14) is expressed as

$$
\frac{\partial Q_{i}}{\partial Q^{(k)}}=Q_{i}^{(k)}, \quad k=1, \ldots, N_{r}, \quad i=1, \ldots, N_{b}
$$

Using (15) and (16), equations (14) take the form

$$
\begin{array}{ll}
\sum_{i=1}^{N_{b}} \frac{Q_{i}^{(\mathrm{RL})}+\sum_{j=1}^{N_{r}} Q_{i}^{(j)} Q^{(j)}}{(E A)_{i}} \cdot Q_{i}^{(k)} L_{i}=0 & \\
\quad \text { or } \delta_{k}^{(\mathrm{RL})}+\sum_{j=1}^{N_{r}} h_{k j} Q^{(j)}=0, & \\
\quad k=1, \ldots, N_{r},
\end{array}
$$


where

$$
\begin{aligned}
\delta_{k}^{(\mathrm{RL})} & =\sum_{i=1}^{N_{b}} \frac{Q_{i}^{(\mathrm{RL})} Q_{i}^{(k)}}{(E A)_{i}} L_{i}, \\
h_{k j} & =\sum_{i=1}^{N_{b}} \frac{Q_{i}^{(j)} Q_{i}^{(k)}}{(E A)_{i}} L_{i} .
\end{aligned}
$$

If there is a real relative displacement $\delta_{k}^{(s)}$ between one end of the redundant member $k$ and the joint at the other end, then equation (17) does not have a zero on the right-hand side and it takes the form

$$
\delta_{k}^{(s)}=\delta_{k}^{(\mathrm{RL})}+\sum_{j=1}^{N_{r}} h_{k j} Q^{(j)}, \quad k=1, \ldots, N_{r} .
$$

Equations (19) can be written in matrix form as follows:

$$
\left[\begin{array}{c}
\delta_{1}^{(s)} \\
\vdots \\
\delta_{N_{r}}^{(s)}
\end{array}\right]=\left[\begin{array}{c}
\delta_{1}^{(\mathrm{RL})} \\
\vdots \\
\delta_{N_{r}}^{(s)}
\end{array}\right]+\left[\begin{array}{ccc}
h_{1, i} & \cdots & h_{1, N_{r}} \\
\vdots & \vdots & \vdots \\
h_{1, N_{r}} & \cdots & h_{N_{r}, N_{r}}
\end{array}\right] \cdot\left[\begin{array}{c}
Q^{(1)} \\
\vdots \\
Q^{\left(N_{r}\right)}
\end{array}\right],
$$

where $Q^{(j)}$ is also expressed in terms of force density $q^{(j)}$ as $Q^{(j)}=q^{(j)} L^{(j)}$. So, equilibrium equations (8) or (12) together with (20) make a system of $2 N+N_{r}$ equations, in the case of planar problems or $3 N+N_{r}$ equations, in the case of $3 \mathrm{D}$ problems, which is solved to give the values of all the unknown forces on the members of the structure. Another way to find the unknown internal forces of the structure is by solving separately the system of linear equations $(20)$ for $Q^{(j)}$. Next, by substituting the known values of $Q^{(j)}$ in (8) or (12) we may find the values of all other forces $Q_{i}$ of the members of the tensegrity structure. However, it is preferable to consider the complete system of $2 N+N_{r}$ or $3 N+N_{r}$ equilibrium equations in order to have the opportunity to investigate the stability of the whole structure.

The existence of solution, for the resulting system of linear equations $\mathbf{K}_{e} \cdot \beta=\gamma$, is an indication of the stability condition of the structure. If the solution exists then it is unique. One can be certain about the existence of the solution when square matrix $\mathbf{K}_{e}$ has one of the following properties [11]:

(1) Matrix $\mathbf{K}_{e}$ has a rank $\rho$ equal to the rank of the augmented matrix $\left(\mathbf{K}_{e} / \gamma\right)$.

(2) The determinant of the square matrix $\mathbf{K}_{e}$ is not equal to zero; that is, $\operatorname{det}\left|\mathbf{K}_{e}\right| \neq 0$.

(3) The inverse $\mathbf{K}_{e}^{-1}$ of the square matrix $\mathbf{K}_{e}$ exists and gives $\mathbf{K}_{e}^{-1} \mathbf{K}_{e}=I$.

(4) The number $n_{\text {ind }}$ of linearly independent rows or columns of matrix $\mathbf{K}_{e}$ is equal to $\rho$.

If matrix $\mathbf{K}_{e}$ does not have one of the above equivalent properties then the solution does not exist and we say that the stability of our tensegrity structure is doubtful.

\section{Numerical Examples}

4.1. The X-Shape 2D Tensegrity Structure. One of the fundamental tensegrity configurations, used by Fuller [4] and Snelson [6] to create more complicated stable structures, is the $\mathrm{X}$-shape $2 \mathrm{D}$ tensegrity truss with $N=4$ nodes (Figure 2(a)). Skelton [12] studied analytically this truss which has four steel cables (elements 1, 2, 5, and 6) and two rods made of an aluminum alloy (members 3 and 4). The technical characteristics of the cables and rods are presented in Table 1. The weight of each joint is $G=0.01 \mathrm{kN}$. No other external loads are applied. Cable 1 in our example is shorter than the required length. During construction one end of the cable is connected to joint 1 and the other is extended by $\delta_{2, \chi}=0.3 \mathrm{~mm}$ to meet joint 2 , as it is explained in the exaggerated detail " $A$ " (Figure 2(b)), which is not to scale.

The complete set of linear equilibrium equations (8), for this problem, consists of $2 \mathrm{~N}=8$ equations. It has $N_{b}+N_{\text {ur }}-$ $2 N=1$ parametric solutions. We say that the structure has a redundancy equal to 1 . Rod 1 is chosen as the redundant member of the structure (Figure 2(a)). Using expression (19) with $\delta_{1}^{(s)}=0.3 \mathrm{~mm}$ and considering that $Q^{(1)}=L_{1,2} q_{1,2}$ we obtain the additional linear equation $-0.0346+7.3246 q_{1,2}=$ 3.16512 which gives $q_{1,2}=0.4368 \mathrm{kN} / \mathrm{m}$. Thus, the value of the force on this element is $F_{1,2}=0.4368 \mathrm{kN}$. Also, this equation is added to equations (12) to give a complete system of linear equations. Expanded matrix $\mathbf{K}_{e}$ of the final system of equations has a nonzero determinant. The results for all forces on the members and the reactions on the supports are tabulated in Table 2 together with those obtained with the DRM. The CEEMFD and the DRM give results which are comparable. However, the CEEMFD is proved to be faster than the DRM (Table 2) because it is a direct method (no iterations are necessary). Also, Table 3 presents the value of the vertical displacement $\delta_{\text {top }, y}$ of joint 3 , obtained by the method, the DRM and the analytic approach proposed by Skelton [12] for the same problem. The results for $\delta_{\text {top }, y}$, with all three methods, are the same. By comparing the results obtained in [2], for an analogous problem of the same geometry, with those obtained in the present work (Tables 2 and 3), one may observe that the numerical results in the current work have values which are almost equal to $10 \%$ of the corresponding values obtained in solving the analogous problem proposed in [2]. This difference was expected due to the linearity existing in both problems and due to the fact that the values of $\delta_{1}^{(s)}$, in the two cases, differ by $90 \%$. The materials used, in both cases, had slightly different properties. It is also verified that the structure passes axial yield and Euler buckling criteria.

4.2. A Weightless $2 D$ Tensegrity Structure. Zhang and Ohsaki [9] use the Adaptive Force Density Method (AFDM) to solve a weightless two-dimensional tensegrity structure which is without any support and out of any gravitational field (Figure 3). This structure has four cables (elements 1,2,3, and 4) and four struts (members 5, 6, 7, and 8). The steel cables and the aluminum rods have the same stiffness which in the current work is chosen to be $(E A)_{r}=(E A)_{c}=12694 \mathrm{kN}$, 


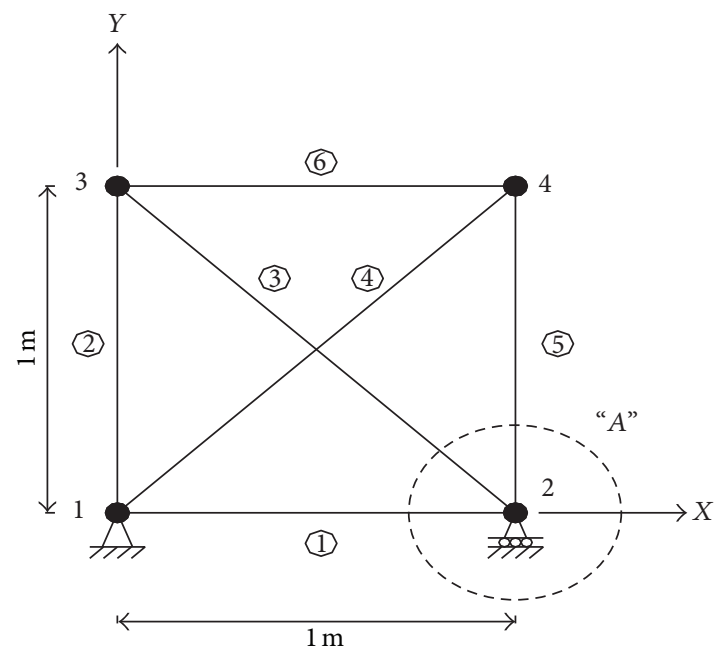

(a)

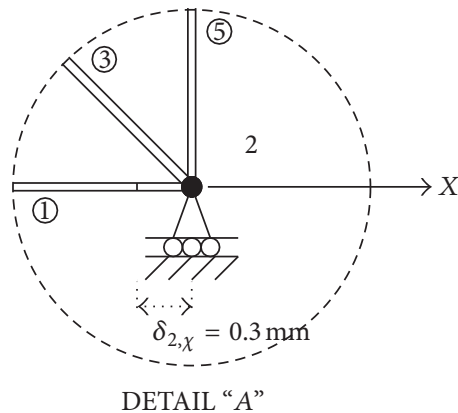

(b)

FIgure 2: (a) The X-shape 2D tensegrity truss. (b) Detail “ $A$ ” of joint 2.

TABLE 1: Technical characteristics of the members of the X-shape $2 \mathrm{D}$ tensegrity.

\begin{tabular}{|c|c|c|c|c|c|c|c|}
\hline Type of member & $\begin{array}{l}\text { Outer diameter } \\
d_{o}(\mathrm{~mm})\end{array}$ & $\begin{array}{l}\text { Inner diameter } \\
d_{i}(\mathrm{~mm})\end{array}$ & $\begin{array}{l}\text { Cross-sectional } \\
\text { area } A\left(\mathrm{~mm}^{2}\right)\end{array}$ & $\begin{array}{c}\text { Moment of } \\
\text { inertia } I_{0}\left(\mathrm{~m}^{4}\right)\end{array}$ & $\begin{array}{c}\text { Specific weight } \gamma \\
\left(\mathrm{kN} / \mathrm{m}^{3}\right)\end{array}$ & $\begin{array}{c}\text { Young's } \\
\text { modulus } E \\
(\mathrm{GPa})\end{array}$ & $\begin{array}{c}\text { Yield stress } \\
\sigma_{y}(\mathrm{MPa})\end{array}$ \\
\hline $\begin{array}{l}\text { Tension } \\
\text { members (steel } \\
\text { cables) }\end{array}$ & 8 & - & 50.24 & - & 78 & 210 & 360 \\
\hline $\begin{array}{l}\text { Compression } \\
\text { members } \\
\text { (aluminum } \\
\text { rods) }\end{array}$ & 40 & 37 & 181.34 & $3.36 \times 10^{-8}$ & 26.50 & 70 & 260 \\
\hline
\end{tabular}

without changing the generality of the problem. Also, the aluminum rods have a hollow cross section with a moment of inertia, about any diameter, equal to $I_{r}=3.36 \times 10^{-8} \mathrm{~m}^{4}$. The only load on the structure is the pretension on cable 1 which is equal to $1 \mathrm{kN}$ (Figure 3). In order to use the CEEMFD we introduce, temporarily, two auxiliary supports at joints 2 and 5 on which there are no reactions (it is as if they do not exist). These supports will only help to define the degree of redundancy. The complete set of linear equilibrium equations (12), for this problem, consists of $2 \mathrm{~N}=$ 10 equations. It has $N_{b}+N_{\text {ur }}-2 N=1$ parametric solutions. Thus, the structure has a redundancy equal to 1 . Cable 1 is chosen as the redundant member. In using the CEEMFD the additional linear equation, which is required in order to find the unknowns, is $-6.8284+6.8284 q_{1,2}=0$, from which one obtains $q_{1,2}=1 \mathrm{kN} / \mathrm{m}$. From the form of matrix $\mathbf{K}_{e}$ it is verified that the structure is stable (i.e., $\left|\mathbf{K}_{e}\right| \neq 0$ ). The same problem is also solved with the DRM and the AFDM [9]. The results are presented in Table 4. One can see that the CEEMFD and the AFDM [9] give results which are comparable and more accurate than those obtained with the DRM. Exactly the same results were obtained and the same observation was made in [2] for an analogous problem of the same geometry but with different material properties. Thus, for this specific problem the results are independent of the

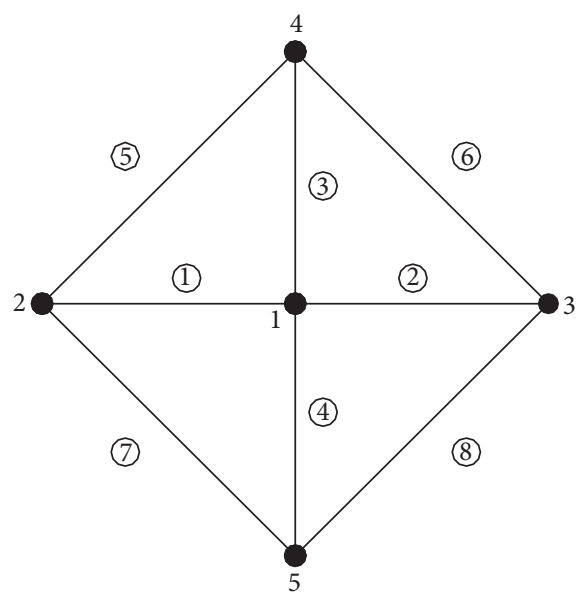

FIGURE 3: A weightless two-dimensional tensegrity truss.

material properties. It is also verified that the structure passes axial yield and Euler buckling criteria.

4.3. A Cantilever 2D Tensegrity Beam. In this subsection, a problem of a cantilever planar tensegrity beam is investigated (Figure 4). This structure is supported at the two leftmost 
TABLE 2: Values of the forces on the members and of the reaction forces on the supports for the X-shape 2D tensegrity structure.

\begin{tabular}{|c|c|c|c|c|c|c|c|c|c|c|}
\hline $\begin{array}{l}\text { Force } \\
\text { density } q_{i, j}\end{array}$ & $\begin{array}{c}\text { Value of } \\
q_{i, j} \text { with } \\
\text { CEEMFD } \\
(\mathrm{kN} / \mathrm{m})\end{array}$ & $\begin{array}{c}\text { Value of } \\
q_{i, j} \text { with } \\
\text { DRM } \\
(\mathrm{kN} / \mathrm{m})\end{array}$ & $\begin{array}{l}\text { Length } L_{i, j} \\
\text { of a } \\
\text { member } \\
\text { (m) }\end{array}$ & $\begin{array}{l}\text { Value of } \\
\text { force } F_{i, j} \\
\text { with } \\
\text { CEEMFD } \\
(\mathrm{kN})\end{array}$ & $\begin{array}{c}\text { Value of } \\
\text { force } F_{i, j} \\
\text { with } \mathrm{DRM} \\
\quad(\mathrm{kN})\end{array}$ & $\begin{array}{l}\text { Reaction } \\
\text { force on a } \\
\text { support }\end{array}$ & $\begin{array}{l}\text { Value of } \\
\text { reaction } \\
\text { with } \\
\text { CEEMFD } \\
(\mathrm{kN})\end{array}$ & $\begin{array}{c}\text { Value of } \\
\text { reaction } \\
\text { with DRM } \\
\quad(\mathrm{kN})\end{array}$ & $\begin{array}{l}\text { CPU time } \\
\text { with } \\
\text { CEEMFD } \\
(\mathrm{sec})\end{array}$ & $\begin{array}{l}\text { CPU time } \\
\text { with DRM } \\
\quad(\mathrm{sec})\end{array}$ \\
\hline$q_{1,2}$ & 0.4368 & 0.4367 & 1.0000 & 0.4368 & 0.4367 & $R_{1, x}$ & 0 & 0 & 0.02 & 2.03 \\
\hline$q_{1,3}$ & 0.4195 & 0.4196 & 1.0000 & 0.4195 & 0.4196 & $R_{2, x}$ & 0 & 0 & & \\
\hline$q_{1,4}$ & -0.4369 & -0.4368 & 1.4142 & -0.6178 & -0.6177 & $R_{1, y}$ & 0.0346 & 0.0345 & & \\
\hline$q_{2,3}$ & -0.4369 & -0.4368 & 1.4142 & -0.6178 & -0.6177 & $R_{2, y}$ & 0.0346 & 0.0345 & & \\
\hline$q_{2,4}$ & 0.4195 & 0.4196 & 1.0000 & 0.4195 & 0.4196 & & & & & \\
\hline$q_{3,4}$ & 0.4368 & 0.4367 & 1.0000 & 0.4368 & 0.4367 & & & & & \\
\hline
\end{tabular}

TABLE 3: Comparison between the results of the CEEMFD and those of the DRM and Skelton's analytic approach.

\begin{tabular}{|c|c|c|c|}
\hline & CEEMFD & DRM & $\begin{array}{l}\text { Skelton's analytic } \\
\text { approach [12] }\end{array}$ \\
\hline $\begin{array}{l}\text { Vertical } \\
\text { displace- } \\
\text { ment of } \\
\text { joint } 3 \text { (in } \\
\mathrm{mm} \text { ) }\end{array}$ & 0.04 & 0.04 & 0.04 \\
\hline
\end{tabular}

nodes 1 and 3 and loaded with a unit vertical force acting at the top-right node 10 (Figure 4). This type of structure was well investigated by Masic et al. [13] who used a nonlinear large displacement model to find its static response and to make a design with optimal mass-to-stiffness ratio. In the present work, no optimization was made. The CEEMFD was simply implemented on this problem, by considering the same geometry proposed by Masic et al. [13] and by arbitrarily choosing the material properties for the rods and the cables. So, this structure has thirteen steel cables (elements 1,2 , $3,4,5,8,9,12,13,16,17,20$, and 21) and eight aluminum struts (members $6,7,10,11,14,15,18$, and 19). The technical characteristics of the cables and rods are given in Table 5 . According to the method, along each one of cables 1, 2, 3, and 4 a pair of opposite axial forces, of value $1 \mathrm{kN}$, is acting each time. Each one of these forces is pushing an end node. Also, a gap exists between the right-end on each one of these members and its nearest joint. This gap is the same for all the four members and is equal to $54.2640 /(E A)_{c}$ or $10 \mathrm{~mm}(0.4 \mathrm{in}$. approx.). The truss is a statically indeterminate structure with a degree of redundancy $N_{r}=N_{b}+N_{\text {ur }}-2 N=4$.

Tensions in cables $1,2,3$, and 4 are chosen as redundancies. Matrix $\mathbf{K}_{e}$ is well-conditioned. The results with CEEMFD are presented in Table 6 together with those of the DRM which was also implemented to this problem. The two methods give results which are comparable. Also, Table 7 gives the values of the vertical displacement $\delta_{y}^{(k)}$ at joints 4 , 6,8 , and 10 obtained by the method and the DRM. The two sets of results are again comparable. One may visualize the deformed shape of this structure by observing the graph in Figure 5, which presents the displacements along its upper side. It is also verified that the structure passes axial yield and Euler buckling criteria.

4.4. A One-Stage 3D Tensegrity Structure. One of the classical tensegrity structures is the one-stage $3 \mathrm{D}$ tensegrity structure (Figure 6) which contains a very basic 2D configuration: the $\mathrm{X}$-shape 2D tensegrity truss. This 3D structure can be made much more complicated by adding more bars and cables and more stages.

In the present work, the X-shape planar truss is formed by bars 5 and 6 and cables 3, 8, and 12, as shown in Figure 6. This stable planar structure is connected with bar 4 with the aid of cables $1,2,7,9,10$, and 11 , to create a stable threedimensional structure. All elements are made of the same precious aluminum alloy. Linear elastic behavior is considered for loads below the yield stress. The technical characteristics of all members are shown in Table 8. Also, the weight of each joint is $G=0.01 \mathrm{kN}$. Cables $1,2,3,10,11$, and 12 have a constant pretension equal to $0.01 \mathrm{kN} / \mathrm{m}$ along their length. The coordinates of all the 6 nodes of the structure are shown on Table 9. In applying the method, the set of equilibrium equations (8) is obtained which has $3 N=18$ independent linear equations. There are $N_{b}+N_{\text {ur }}=12+$ $3 \times 3=21$ unknowns indicating a degree of redundancy equal to 3. However, since tensions in cables 1,2 , and 3 have no effect on the values of force densities of the other members, one has $q_{1,2}=q_{1,3}=q_{2,3}=0.01 \mathrm{kN} / \mathrm{m}$. Then, the number of the unknowns is reduced to 18 . Thus, the system of 18 linear equations is sufficient to give the solution to our problem. Matrix $\mathbf{K}_{e}$ of the linear system of equations has all the properties given by statements (1) to (4) of Section 3, verifying that our tensegrity structure is stable as expected.

The values of the reaction forces on the supports and of all the forces and the corresponding force densities on the members of the structure are presented in Table 10. Also, it is verified that for this $3 \mathrm{D}$ problem the structure passes axial yield and Euler buckling criteria.

4.5. A Two-Stage Self-Stressed 3D Tensegrity Structure. Zhang and Ohsaki [9] have also solved the problem of a two-stage self-stressed 3D tensegrity structure (Figure 7) by using the AFDM. In this example, the structure is considered to be 
TABLE 4: Values of the forces on the members for the weightless 2D tensegrity structure.

\begin{tabular}{|c|c|c|c|c|c|c|c|}
\hline $\begin{array}{l}\text { Force density } \\
q_{i, j}\end{array}$ & $\begin{array}{c}\text { Value of } q_{i, j} \text { with } \\
\text { CEEMFD } \\
(\mathrm{kN} / \mathrm{m})\end{array}$ & $\begin{array}{c}\text { Value of } q_{i, j} \text { with } \\
\text { AFDM [9] } \\
(\mathrm{kN} / \mathrm{m})\end{array}$ & $\begin{array}{c}\text { Value of } q_{i, j} \text { with } \\
\text { DRM }(\mathrm{kN} / \mathrm{m})\end{array}$ & $\begin{array}{l}\text { Length } L_{i, j} \text { of a } \\
\text { member }(\mathrm{m})\end{array}$ & $\begin{array}{c}\text { Value of } F_{i, j} \\
\text { with method } \\
\text { CEEMFD }(\mathrm{kN})\end{array}$ & $\begin{array}{c}\text { Value of } F_{i, j} \\
\text { with method } \\
\text { AFDM [9] }(\mathrm{kN})\end{array}$ & $\begin{array}{c}\text { Value of force } \\
F_{i, j} \text { with } \\
\text { DRM }(\mathrm{kN}) \\
\end{array}$ \\
\hline$q_{1,2}$ & 1.00000000 & 1.00000000 & 1.00000072 & 1.00000000 & 1.00000000 & 1.00000000 & 1.00000072 \\
\hline$q_{1,3}$ & 1.00000000 & 1.00000000 & 1.00000072 & 1.00000000 & 1.00000000 & 1.00000000 & 1.00000072 \\
\hline$q_{1,4}$ & 1.00000000 & 1.00000000 & 1.00000072 & 1.00000000 & 1.00000000 & 1.00000000 & 1.00000072 \\
\hline$q_{1,5}$ & 1.00000000 & 1.00000000 & 1.00000072 & 1.00000000 & 1.00000000 & 1.00000000 & 1.00000072 \\
\hline$q_{2,4}$ & -0.50000000 & -0.50000000 & -0.50000036 & 1.41421356 & -0.70710678 & -0.70710678 & -0.70710729 \\
\hline$q_{2,5}$ & -0.50000000 & -0.50000000 & -0.50000036 & 1.41421356 & -0.70710678 & -0.70710678 & -0.70710729 \\
\hline$q_{3,4}$ & -0.50000000 & -0.50000000 & -0.50000036 & 1.41421356 & -0.70710678 & -0.70710678 & -0.70710729 \\
\hline$q_{3,5}$ & -0.50000000 & -0.50000000 & -0.50000036 & 1.41421356 & -0.70710678 & -0.70710678 & -0.70710729 \\
\hline
\end{tabular}

TABLE 5: Technical characteristics of the members of the cantilever 2D tensegrity beam.

\begin{tabular}{|c|c|c|c|c|c|c|c|}
\hline Type of member & $\begin{array}{l}\text { Outer diameter } \\
\qquad d_{o}(\mathrm{~mm})\end{array}$ & $\begin{array}{l}\text { Inner diameter } \\
d_{i}(\mathrm{~mm})\end{array}$ & $\begin{array}{l}\text { Cross sec. area } \\
\qquad A\left(\mathrm{~mm}^{2}\right)\end{array}$ & $\begin{array}{c}\text { Moment of } \\
\text { inertia } I_{0}\left(\mathrm{~m}^{4}\right)\end{array}$ & $\begin{array}{c}\text { Specific weight } \gamma \\
\left(\mathrm{kN} / \mathrm{m}^{3}\right)\end{array}$ & $\begin{array}{c}\text { Young's } \\
\text { modulus } E \\
(\mathrm{GPa})\end{array}$ & $\begin{array}{c}\text { Yield stress } \\
\sigma_{y}(\mathrm{MPa})\end{array}$ \\
\hline $\begin{array}{l}\text { Tension } \\
\text { members (steel } \\
\text { cables) }\end{array}$ & 5.74 & - & 25.84 & - & 78 & 210 & 480 \\
\hline $\begin{array}{l}\text { Compression } \\
\text { members (alum. } \\
\text { rods) }\end{array}$ & 77 & 75 & 238.76 & $1.72 \times 10^{-7}$ & 26.50 & 70 & 260 \\
\hline
\end{tabular}

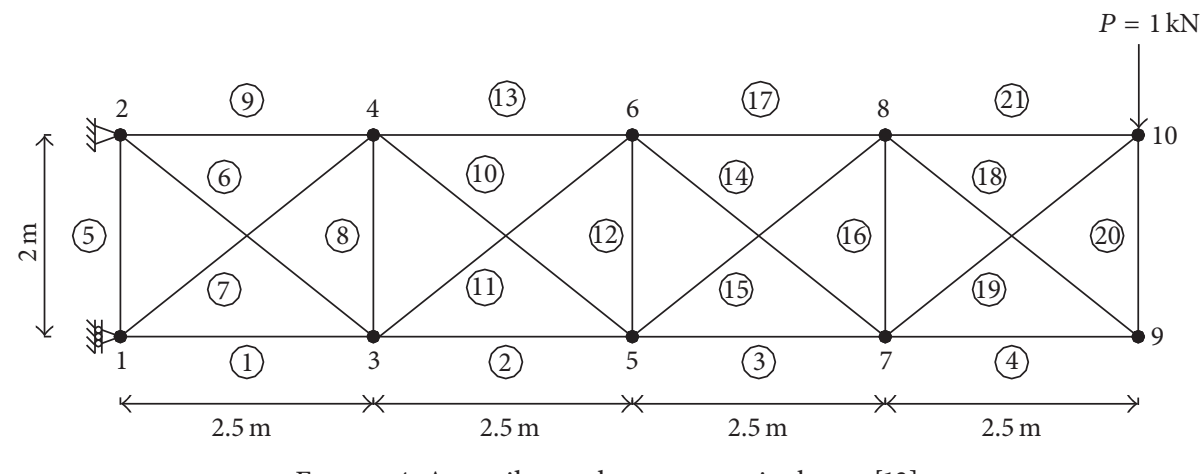

FIGURE 4: A cantilever planar tensegrity beam [13].

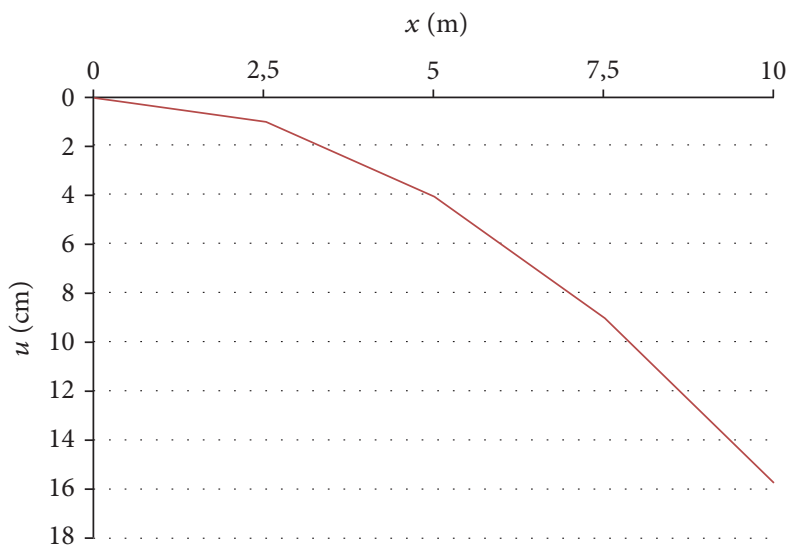

FIGURE 5: Vertical displacements along the upper side of the tensegrity beam. 
TABLE 6: Values of the forces on the members for the cantilever 2D tensegrity beam.

\begin{tabular}{|c|c|c|c|c|c|c|}
\hline & $\begin{array}{c}\text { Value of } q_{i, j} \text { with } \\
\text { CEEMFD } \\
(\mathrm{kN} / \mathrm{m}) \\
\text { CPU time }= \\
0.07 \mathrm{sec}\end{array}$ & $\begin{array}{c}\text { Value of } q_{i, j} \text { with } \\
\text { DRM }(\mathrm{kN} / \mathrm{m}) \\
\text { CPU time }= \\
8.25 \mathrm{sec}\end{array}$ & $\begin{array}{c}\text { Length } L_{i, j} \text { of a } \\
\text { member }(\mathrm{m})\end{array}$ & $\begin{array}{l}\text { Value of force } \\
F_{i, j} \text { with } \\
\text { CEEMFD }(\mathrm{kN})\end{array}$ & $\begin{array}{c}\text { Value of force } \\
F_{i, j} \text { with DRM } \\
(\mathrm{kN})\end{array}$ & $\begin{array}{c}\text { Value of stress } \\
\boldsymbol{\sigma}_{i, j} \text { with } \\
\text { CEEMFD } \\
(\mathrm{MPa})\end{array}$ \\
\hline \multicolumn{7}{|c|}{ Force density } \\
\hline \multicolumn{7}{|l|}{$q_{i, j}$} \\
\hline$q_{1,2}$ & 0.240633 & 0.240613 & 2.5000 & 0.601583 & 0.601533 & 23.2811 \\
\hline$q_{2,5}$ & 0.651541 & 0.651521 & 2.5000 & 1.628852 & 1.628802 & 63.0361 \\
\hline$q_{5,7}$ & 1.196278 & 1.196278 & 2.5000 & 2.990696 & 2.990696 & 115.7390 \\
\hline$q_{7,9}$ & 1.966444 & 1.966444 & 2.5000 & 4.916110 & 4.916110 & 190.2519 \\
\hline$q_{1,3}$ & 2.461283 & 2.461415 & 2.0000 & 4.922566 & 4.922830 & 190.5018 \\
\hline$q_{2,3}$ & -1.861511 & -1.861511 & 3.2016 & -5.959814 & -5.959814 & -24.9615 \\
\hline$q_{1,4}$ & -2.454204 & -2.454336 & 3.2016 & -7.857380 & -7.857803 & -32.9091 \\
\hline$q_{2,4}$ & 4.147074 & 4.147074 & 2.0000 & 8.294147 & 8.294147 & 320.9809 \\
\hline$q_{3,4}$ & 4.075133 & 4.075096 & 2.5000 & 10.187833 & 10.187740 & 394.2660 \\
\hline$q_{4,5}$ & -1.705920 & -1.705788 & 3.2016 & -5.461675 & -5.461252 & -22.8752 \\
\hline$q_{2,6}$ & -2.272414 & -2.272414 & 3.2016 & -7.275360 & -7.275360 & -30.4714 \\
\hline$q_{5,6}$ & 3.969719 & 3.969475 & 2.0000 & 7.939438 & 7.938949 & 307.2538 \\
\hline$q_{4,6}$ & 3.326840 & 3.326539 & 2.5000 & 8.317101 & 8.316348 & 321.8692 \\
\hline$q_{6,7}$ & -1.710358 & -1.710114 & 3.2016 & -5.475883 & -5.475101 & -22.9347 \\
\hline$q_{5,8}$ & -2.250652 & -2.250539 & 3.2016 & -7.205687 & -7.205327 & -30.1796 \\
\hline$q_{7,8}$ & 4.204022 & 4.203534 & 2.0000 & 8.408044 & 8.407068 & 325.3887 \\
\hline$q_{6,8}$ & 2.764778 & 2.764233 & 2.5000 & 6.911946 & 6.910582 & 267.4902 \\
\hline$q_{8,9}$ & -1.966421 & -1.966045 & 3.2016 & -6.295692 & -6.294490 & -26.3683 \\
\hline$q_{7,10}$ & -2.480514 & -2.480270 & 3.2016 & -7.941615 & -7.940834 & -33.2619 \\
\hline$q_{9,10}$ & 1.973494 & 1.973118 & 2.0000 & 3.946987 & 3.946236 & 152.7472 \\
\hline$q_{8,10}$ & 2.480544 & 2.479735 & 2.5000 & 6.201359 & 6.199338 & 239.9907 \\
\hline \multicolumn{7}{|c|}{ Reaction (kN) } \\
\hline$R_{H}^{(1)}$ & & & & 5.534000 & 5.534380 & \\
\hline$R_{H}^{(3)}$ & & & & -5.534000 & -5.533907 & \\
\hline$R_{v}^{(3)}$ & & & & 1.213600 & 1.213864 & \\
\hline
\end{tabular}

TABLE 7: Displacements with the CEEMFD and the DRM along the tensegrity beam.

\begin{tabular}{|c|c|c|c|c|c|}
\hline Joint $i$ & 1 & 4 & 6 & 8 & 10 \\
\hline $\begin{array}{l}\text { Vertical displacement of joint } i \text { with } \\
\text { CEEMFD }\end{array}$ & 0.0000 & $1.0091 \mathrm{~cm}$ or $0.40 \mathrm{in}$. & $4.1011 \mathrm{~cm}$ or $1.61 \mathrm{in}$. & $9.0438 \mathrm{~cm}$ or $3.56 \mathrm{in}$. & $15.7700 \mathrm{~cm}$ or $6.21 \mathrm{in}$ \\
\hline $\begin{array}{l}\text { Vertical displacement of joint } i \text { with } \\
\text { DRM }\end{array}$ & 0.0000 & $1.0091 \mathrm{~cm}$ or $0.40 \mathrm{in}$. & $4.1012 \mathrm{~cm}$ or $1.61 \mathrm{in}$. & $9.0467 \mathrm{~cm}$ or $3.56 \mathrm{in}$. & $15.7779 \mathrm{~cm}$ or $6.21 \mathrm{in}$ \\
\hline
\end{tabular}

TABLE 8: Technical characteristics of the one-stage 3D tensegrity structure.

\begin{tabular}{|c|c|c|c|c|c|c|c|}
\hline Type of member & $\begin{array}{l}\text { Outer diameter } \\
d_{o}(\mathrm{~mm})\end{array}$ & $\begin{array}{l}\text { Inner diameter } \\
d_{i}(\mathrm{~mm})\end{array}$ & $\begin{array}{l}\text { Cross-sectional } \\
\text { area } A\left(\mathrm{~mm}^{2}\right)\end{array}$ & $\begin{array}{l}\text { Moment of } \\
\text { inertia } I_{0}\left(\mathrm{~m}^{4}\right)\end{array}$ & $\begin{array}{c}\text { Specific weight } \gamma \\
\left(\mathrm{kN} / \mathrm{m}^{3}\right)\end{array}$ & $\begin{array}{l}\text { Young's } \\
\text { modulus } E \\
(\mathrm{GPa})\end{array}$ & $\begin{array}{c}\text { Yield stress } \\
\sigma_{y}(\mathrm{MPa})\end{array}$ \\
\hline $\begin{array}{l}\text { Tension members } \\
\text { (aluminium cables) }\end{array}$ & 20 & - & 314.16 & - & 31.85 & 89.17 & 260 \\
\hline $\begin{array}{l}\text { Compression } \\
\text { elements } 4 \text { \& } 6 \\
\text { (aluminum rods) }\end{array}$ & 63.9 & 61.7 & 214.87 & $1.07 \times 10^{-7}$ & 31.85 & 89.17 & 260 \\
\hline $\begin{array}{l}\text { Compression } \\
\text { element } 5 \\
\text { (aluminum rod) }\end{array}$ & 58.4 & 54.9 & 311.45 & $1.25 \times 10^{-7}$ & 31.85 & 89.17 & 260 \\
\hline
\end{tabular}




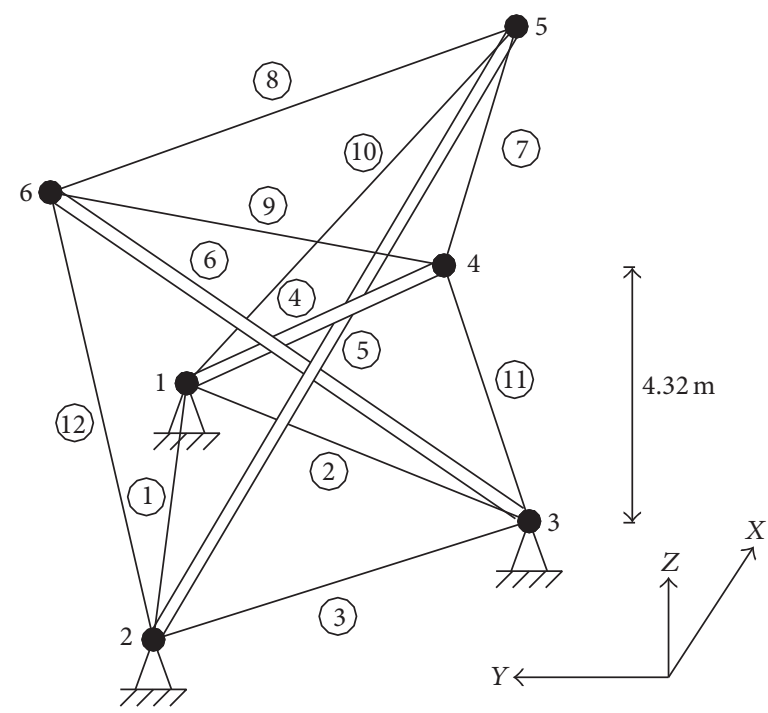

FIgURE 6: A one-stage 3D tensegrity structure.

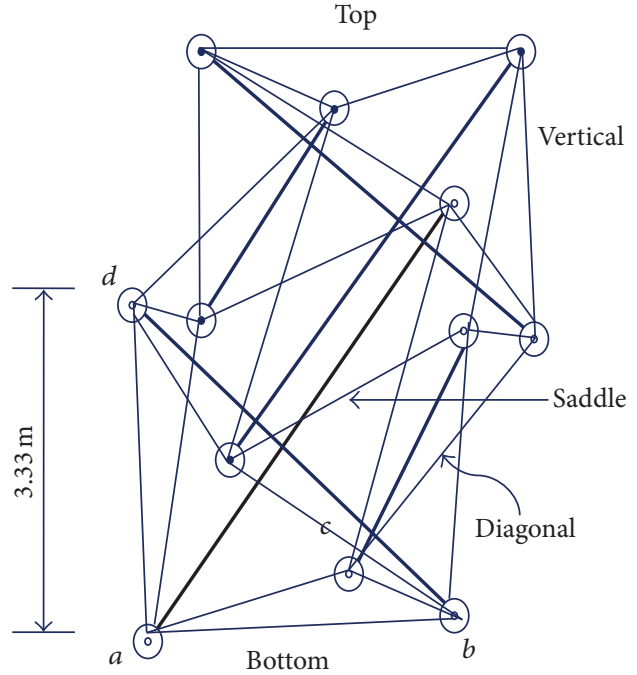

FIgURE 7: A two-stage 3D tensegrity structure (perspective view).

TABLE 9: Values of the coordinates of the joints of the one-stage 3D tensegrity structure.

\begin{tabular}{lccc}
\hline Node $i$ & $x_{i}(\mathrm{~m})$ & $y_{i}(\mathrm{~m})$ & $z_{i}(\mathrm{~m})$ \\
\hline 1 & 3.0 & -1.73205 & 0.0 \\
2 & 0.0 & 3.46410 & 0.0 \\
3 & -3.0 & -1.73205 & 0.0 \\
4 & -4.618802 & 0.0 & 4.32049 \\
5 & -0.479058 & -0.82975 & 4.32049 \\
6 & 2.309401 & 4.0 & 4.32049 \\
\hline
\end{tabular}

weightless and is composed of 12 nodes and 30 members; that is, $N=12$ and $N_{b}=30$.

The structure contains 24 steel cables and 6 aluminum rods. The 24 cables are divided into four groups: (i) cables of the top and bottom bases, (ii) saddle cables, (iii) vertical cables, and (iv) diagonal cables, as indicated clearly in Figure 7. Its six rods are divided in two groups: (1) rods of the upper stage; (2) rods of the lower stage. Thus, in total, we have six groups of elements. Since the initial force densities and independent nodal coordinates can be arbitrarily specified, one can have some control over the geometrical and mechanical properties of the structure. Thus, the steel cables and the aluminum rods have equal stiffness $(E A)_{r}=(E A)_{c}=5426 \mathrm{kN}$. Also, the aluminum rods have a hollow cross section with a moment of inertia, about any diameter, equal to $I_{r}=2.894 \times 10^{-9} \mathrm{~m}^{4}$. The only loading on the structure is the initial set of force densities $q^{(o)}$ applied in cables of all the six groups; that is, for the two groups of rods it is $q_{r}^{(o)}=-1.5 \mathrm{kN} / \mathrm{m}$, for the saddle cables is $q_{s}^{(o)}=2.0 \mathrm{kN} / \mathrm{m}$, and for all the other cables is $q_{c}^{(o)}=1.0 \mathrm{kN} / \mathrm{m}$.

By specifying the coordinates of nodes $a, b$, and $c$, which are shown in Figure 7, to make the bottom base located on the $x y$-plane, and node $d$ in the lower stage, we can have the configuration of the tensegrity structure as shown in Figure 7. The coordinates of these nodes are shown in Table 11. Then, the CEEMFD gives the set of final values of force densities, for the six groups of elements, which is listed in Table 12. These values are compared with those obtained with the AFDM, after 158 iterations [9]. The two sets of solutions compare favorably but in CEEMFD the solution is obtained directly. It is verified that the structure passes axial yield and Euler buckling criteria.

\section{Conclusions}

We have presented the CEEMFD to analyze 2D and 3D tensegrity structures. The resulting final linear system of equilibrium equations can be directly solved to give a unique solution for the force densities on the elements of the structure. For stable statically determinate structures, the global matrix 
TABLE 10: Values of the forces on the members of the one-stage 3D structure.

\begin{tabular}{|c|c|c|c|c|c|c|c|c|}
\hline $\begin{array}{l}\text { Force density } \\
\text { on a member }\end{array}$ & $\begin{array}{l}\text { Value of } q_{i, j} \\
\text { with } \\
\text { CEEMFD } \\
(\mathrm{kN} / \mathrm{m})\end{array}$ & $\begin{array}{l}\text { Value of } q_{i, j} \\
\text { with DRM } \\
\quad(\mathrm{kN} / \mathrm{m})\end{array}$ & $\begin{array}{l}\text { Length } L_{i, j} \text { of } \\
\text { a member } \\
\text { (m) }\end{array}$ & $\begin{array}{c}\text { Value of } F_{i, j} \\
\text { with } \\
\text { CEEMFD } \\
(\mathrm{kN})\end{array}$ & $\begin{array}{l}\text { Value of } F_{i, j} \\
\text { with DRM } \\
\quad(\mathrm{kN})\end{array}$ & $\begin{array}{l}\text { Reaction } \\
\text { force on a } \\
\text { support }\end{array}$ & $\begin{array}{l}\text { Value of } \\
\text { reaction force } \\
\text { with } \\
\text { CEEMFD } \\
(\mathrm{kN})\end{array}$ & $\begin{array}{l}\text { Value of } \\
\text { reaction force } \\
\text { with DRM } \\
(\mathrm{kN})\end{array}$ \\
\hline$q_{1,2}$ & 0.010000 & 0.010000 & 6.000000 & 0.060000 & 0.060000 & $R_{1, x}$ & 0.321956 & 0.322034 \\
\hline$q_{1,3}$ & 0.010000 & 0.010000 & 6.000000 & 0.060000 & 0.060000 & $R_{2, x}$ & -0.207729 & -0.207787 \\
\hline$q_{1,4}$ & -0.093977 & -0.093998 & 8.928200 & -0.839048 & -0.839231 & $R_{3, x}$ & 0.529678 & 0.529822 \\
\hline$q_{1,5}$ & 0.077393 & 0.077414 & 5.620020 & 0.434951 & 0.435068 & $R_{1, y}$ & -0.031957 & -0.031974 \\
\hline$q_{2,3}$ & 0.010000 & 0.010000 & 6.000000 & 0.060000 & 0.060000 & $R_{2, y}$ & 0.423712 & 0.423814 \\
\hline$q_{2,5}$ & -0.114623 & -0.114644 & 6.110100 & -0.700357 & -0.700484 & $R_{3, y}$ & 0.391755 & 0.391837 \\
\hline$q_{2,6}$ & 0.056172 & 0.056193 & 4.928199 & 0.276828 & 0.276931 & $R_{1, z}$ & 0.157097 & 0.157097 \\
\hline$q_{3,4}$ & 0.054744 & 0.054765 & 4.928199 & 0.269789 & 0.269892 & $R_{2, z}$ & 0.334522 & 0.334524 \\
\hline$q_{3,6}$ & -0.096973 & -0.096994 & 8.928200 & -0.865798 & -0.865984 & $R_{3, z}$ & 0.264438 & 0.264437 \\
\hline$q_{4,5}$ & 0.125318 & 0.125340 & 4.222079 & 0.529100 & 0.529194 & & & \\
\hline$q_{4,6}$ & 0.013337 & 0.013342 & 8.000000 & 0.106699 & 0.106736 & & & \\
\hline$q_{5,6}$ & 0.096702 & 0.096720 & 5.576919 & 0.539297 & 0.539401 & & & \\
\hline
\end{tabular}

TABLE 11: Specified nodal coordinates in the two-stage 3D tensegrity structure.

\begin{tabular}{lccc}
\hline Node $i$ & $x_{i}(\mathrm{~m})$ & $y_{i}(\mathrm{~m})$ & $z_{i}(\mathrm{~m})$ \\
\hline$a$ & -2.6667 & 0.0000 & 0.0000 \\
$b$ & 1.3333 & -2.3094 & 0.0000 \\
$c$ & 1.3334 & 2.3094 & 0.0000 \\
$d$ & -1.8867 & 1.6666 & 3.3333 \\
\hline
\end{tabular}

TABLE 12: Force densities in the members of the two-stage 3D tensegrity structure.

\begin{tabular}{|c|c|c|c|c|c|c|}
\hline Group $\rightarrow$ & $\begin{array}{c}\text { Rods of the upper } \\
\text { stage (1) }\end{array}$ & $\begin{array}{c}\text { Rods of the lower } \\
\text { stage (2) }\end{array}$ & $\begin{array}{l}\text { Cables (top \& } \\
\text { bottom) (i) }\end{array}$ & Saddle cables (ii) & Vertical cables (iii) & $\begin{array}{l}\text { Diagonal cables } \\
\text { (iv) }\end{array}$ \\
\hline $\begin{array}{l}\text { Initial value } \\
(\mathrm{kN} / \mathrm{m})\end{array}$ & -1.5000 & -1.5000 & 1.0000 & 2.0000 & 1.0000 & 1.0000 \\
\hline $\begin{array}{l}\text { Final value } \\
\text { (CEEMFD) }\end{array}$ & -1.8376 & -1.8376 & 0.9282 & 1.9920 & 1.1735 & 0.9957 \\
\hline $\begin{array}{l}\text { Final value } \\
(\text { AFDM) [9] }\end{array}$ & -1.8376 & -1.8376 & 0.9281 & 1.9918 & 1.1737 & 0.9958 \\
\hline
\end{tabular}

$\mathbf{K}_{e}$ of the final system of equilibrium equations is square and has a nonzero determinant. For statically indeterminate structures, this matrix is not square. It is expanded to a square matrix after the implementation of Castigliano's theorem which gives the additional equations required for the solution. The partial derivatives, which appear in the additional equations, are replaced by statically acceptable internal forces which are applied on the structure. For stable structures, the complete system of equations is then solved to give the values of the force densities on the members of the structure. Five problems of both planar and spatial tensegrity structures were solved. The results compare favorably with those obtained with the DRM and the AFDM [9] but the CEEMFD is faster as a direct method. As for future work we consider the extension of the method for geodesic domes and tensegrity bridges for pedestrians.

\section{Competing Interests}

The authors declare that there is no conflict of interests regarding the publication of this article.

\section{References}

[1] P. Christou, A. Michael, and M. Elliotis, "Implementing slack cables in the force density method," Engineering Computations, vol. 31, no. 5, pp. 1011-1030, 2014.

[2] M. Elliotis, P. Christou, and A. Michael, "Analysis of planar and spatial tensegrity structures with redundancies, by implementing a comprehensive equilibrium equations method," International Journal of Engineering Science and Technology, vol. 5, pp. 40-55, 2016. 
[3] H.-J. Schek, "The force density method for form finding and computation of general networks," Computer Methods in Applied Mechanics and Engineering, vol. 3, no. 1, pp. 115-134, 1974.

[4] R. B. Fuller, Synergetics. Explorations in the Geometry of Thinking, Macmillan, New York, NY, USA, 1975.

[5] D. Emmerich, "Constructions de reseaux autodendantes," Patent no. 1, 377, 290, 1963.

[6] K. Snelson, "Continuous tension, discontinuous compression structures," US Patent No. 3, 169, 611, 1965.

[7] M. Papadrakakis, "A method for the automatic evaluation of the dynamic relaxation parameters," Computer Methods in Applied Mechanics and Engineering, vol. 25, no. 1, pp. 35-48, 1981.

[8] S. H. Juan and J. M. Mirats Tur, "Tensegrity frameworks: static analysis review," Mechanism and Machine Theory, vol. 43, no. 7, pp. 859-881, 2008.

[9] J. Y. Zhang and M. Ohsaki, "Adaptive force density method for form-finding problem of tensegrity structures," International Journal of Solids and Structures, vol. 43, no. 18-19, pp. 5658-5673, 2006.

[10] Y. C. Fung, Foundations of Solid Mechanics, Prentice Hall, New Jersey, NJ, USA, 1977.

[11] T. Sauer, Numerical Analysis, Pearson Education, Upper Saddle River, NJ, USA, 2005.

[12] R. E. Skelton, Dynamics and Control of Aerospace Systems, CRC Press, New York, NY, USA, 2002.

[13] M. Masic, R. E. Skelton, and P. E. Gill, "Algebraic tensegrity form-finding," International Journal of Solids and Structures, vol. 42, no. 16-17, pp. 4833-4858, 2005. 


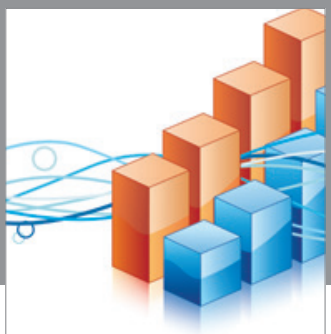

Advances in

Operations Research

vatem alat4

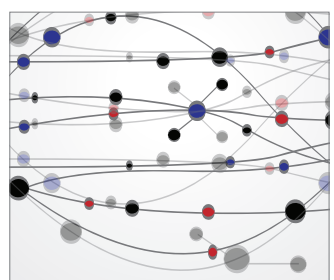

\section{The Scientific} World Journal
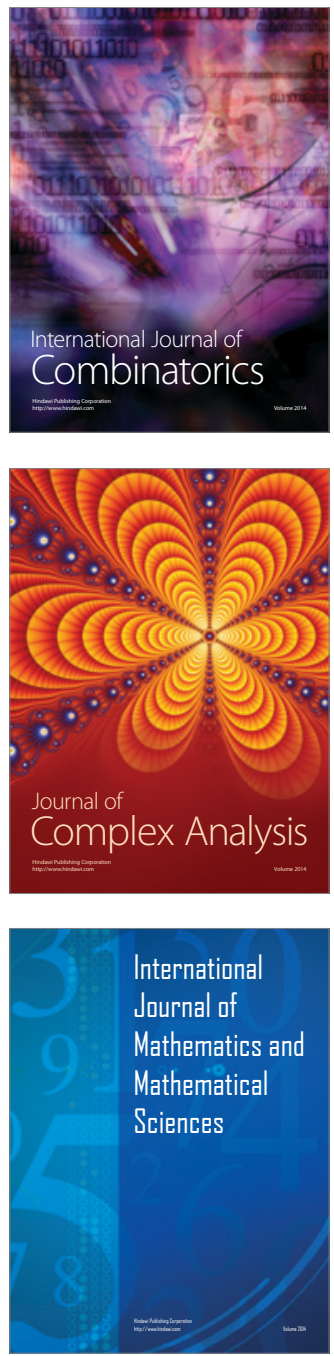
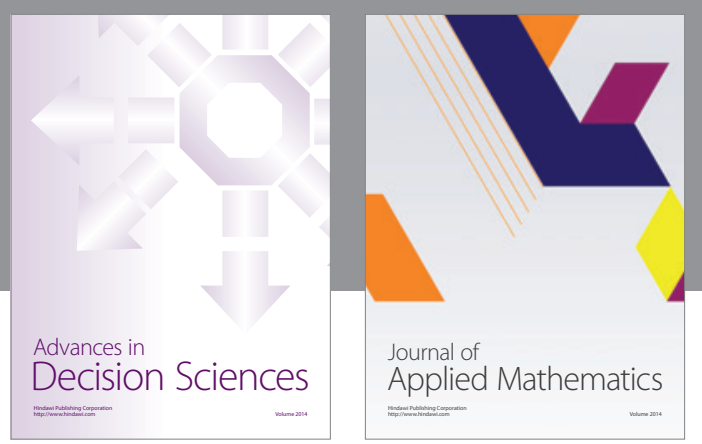

Algebra

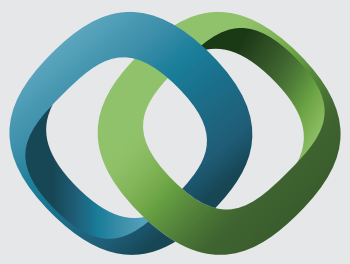

\section{Hindawi}

Submit your manuscripts at

http://www.hindawi.com
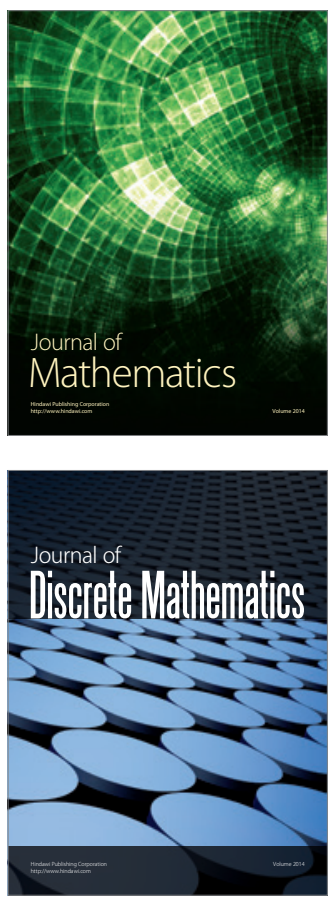

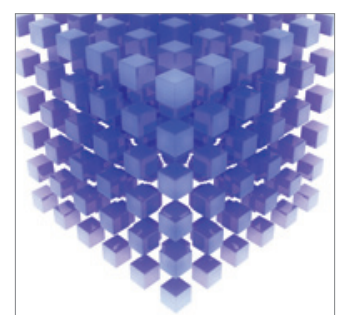

Mathematical Problems in Engineering
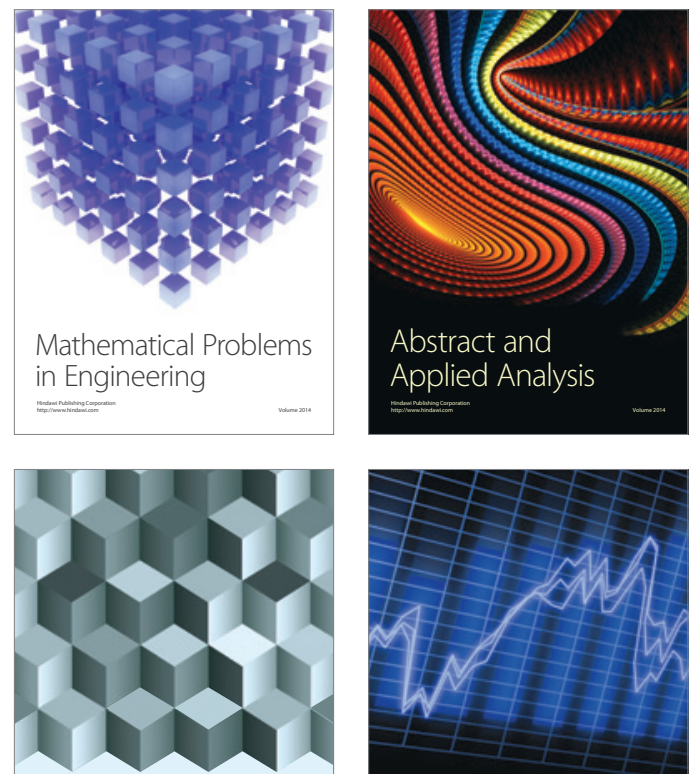

Journal of

Function Spaces

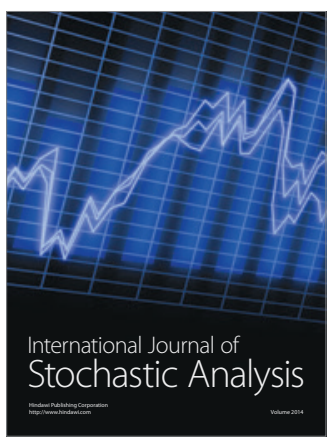

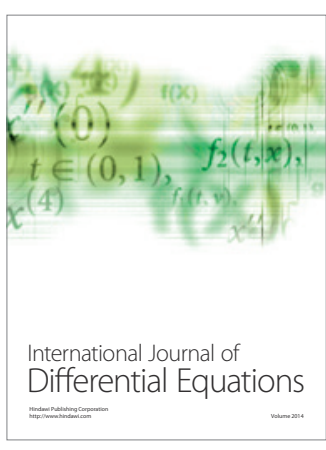
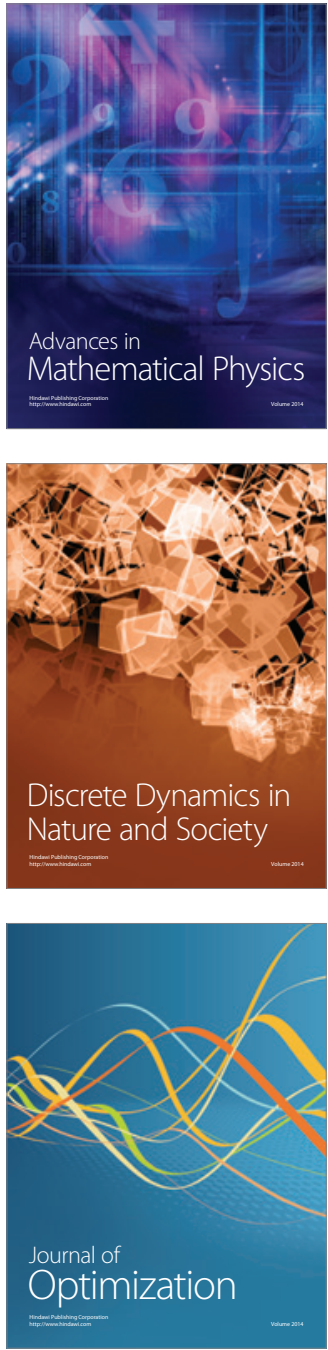